$\mathrm{DOE} / \mathrm{ER} / 45417-25$

\title{
STRUCTURAL, ELECTRONIC AND CHEMICAL PROPERTIES OF METAL/OXIDE AND OXIDE/OXIDE INTERFACES AND THIN FILM STRUCTURES
}

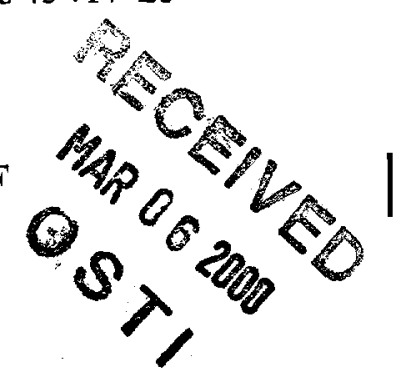

Final Technical Progress Report

for Period August 1, 1990 - July 31, 1999

Robert J. Lad

Laboratory for Surface Science \& Technology

and Department of Physics \& Astronomy

University of Maine

Orono, ME 04469-5764

December 1999

Prepared for

We have no objection from a patent
etandpolnt to the publication or
dissemination of this

dissemination of this material.

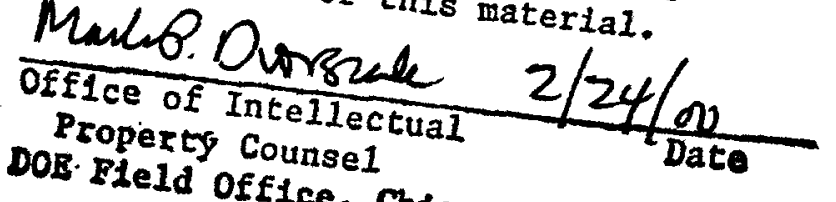

DOE. Fleld Offinse1

The U.S. DEPARTMENT OF ENERGY

AGREEMENT NO. DE-FG02-90ER45417

\begin{abstract}
NOTICE
This report was prepared as an account of work sponsored by the United States Government. Neither the United States nor the Department of Energy, nor any of their employees, nor any of their contractors, subcontractors, or their employees, makes any warranty, express or implied, or assumes any legal liability or responsibility for the accuracy, completeness, or usefulness of any information, apparatus, product or process disclosed or represents that its use would not infringe privately-owned rights.
\end{abstract}




\section{DISCLAIMER}

This report was prepared as an account of work sponsored by an agency of the United States Government. Neither the United States Government nor any agency thereof, nor any of their employees, make any warranty, express or implied, or assumes any legal liability or responsibility for the accuracy, completeness, or usefulness of any information, apparatus, product, or process disclosed, or represents that its use would not infringe privately owned rights. Reference herein to any specific commercial product, process, or service by trade name, trademark, manufacturer, or otherwise does not necessarily constitute or imply its endorsement, recommendation, or favoring by the United States Government or any agency thereof. The views and opinions of authors expressed herein do not necessarily state or reflect those of the United States Government or any agency thereof. 


\section{DISCLAIMER}

Portions of this document may be illegible in electronic image products. Images are produced from the best available original document. 


\title{
Table of Contents
}

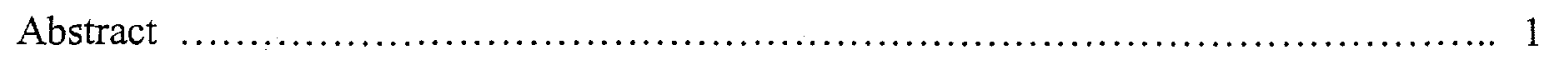

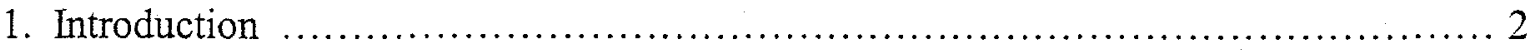

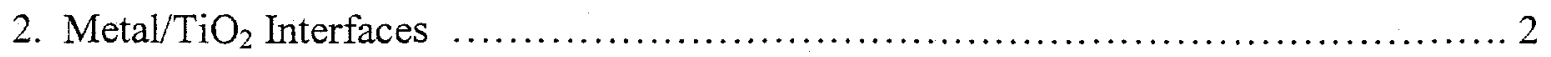

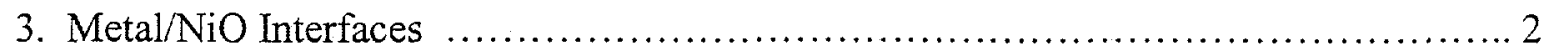

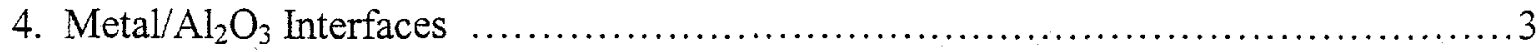

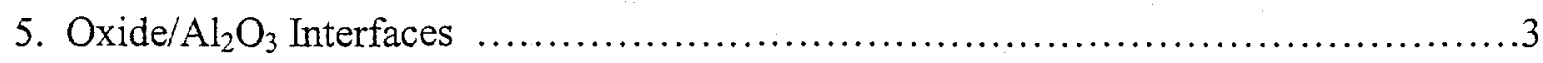

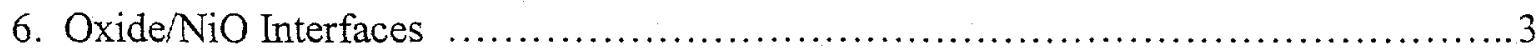

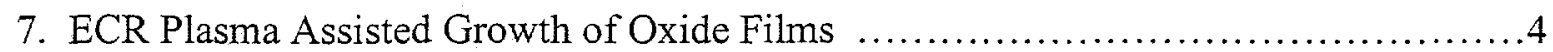

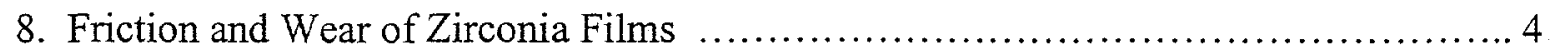

9. Graduate Student Degrees Resulting from the Project $\ldots \ldots \ldots \ldots \ldots \ldots \ldots \ldots \ldots \ldots \ldots$

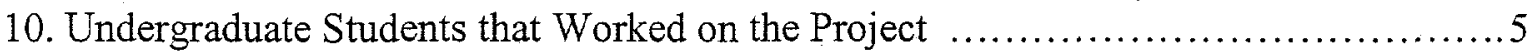

11. Publications Resulting from DOE Grant \#DE-FG02-90ER45417 ................6 6

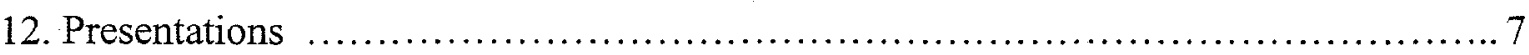

\begin{abstract}
$\underline{\text { Abstract }}$
This project focused on three different aspects of oxide thin film systems: (i) Model metal/oxide and oxide/oxide interface studies were carried out by depositing ultra-thin metal ( $\mathrm{Al}, \mathrm{K}, \mathrm{Mg}$ ) and oxide $\left(\mathrm{MgO}, \mathrm{AlO}_{\mathrm{x}}\right)$ films on $\mathrm{TiO}_{2}, \mathrm{NiO}$ and $\alpha-\mathrm{Al}_{2} \mathrm{O}_{3}$ single crystal oxide substrates. (ii) Electron cyclotron resonance (ECR) oxygen plasma deposition was used to fabricate $\mathrm{AlO}_{\mathrm{x}}$ and $\mathrm{ZrO}_{2}$ films on sapphire substrates, and film growth mechanisms and structural characteristics were investigated. (iii) The friction and wear characteristics of $\mathrm{ZrO}_{2}$ films on sapphire substrates in unlubricated sliding contact were studied and correlated with film microstructure. In these studies, thin film and interfacial regions were characterized using diffraction (RHEED, LEED, XRD), electron spectroscopies (XPS, UPS, AES), microscopy (AFM) and tribology instruments (pin-on-disk, friction microprobe, and scratch tester). By precise control of thin film microstructure, an increased understanding of the structural and chemical stability of interface regions and tribological performance of ultra-thin oxide films was achieved in these important ceramic systems.
\end{abstract}




\section{Introduction}

Oxide-based ceramic films are important technological materials in a wide range of applications including hard and wear-resistant coatings, passivation layers for high temperature structural materials, nanolaminate composites, catalytic supports, and solid state sensors and transducers. In this research project, fundamental studies were carried out to investigate the structural, electronic, chemical, and mechanical properties of metal/oxide interfaces and oxide/oxide interfaces. In addition to studying interfacial phenomena such as thermal stability, chemical reactivity, interdiffusion and interfacial impurity effects, the synthesis/property relationships of ultra-thin oxide films were investigated. In particular, ECR oxygen-plasma-assisted growth was used to manipulate the microstructure of heteroepitaxial oxide films. Thin oxide films grown in this manner have well-defined structures and controlled defect distributions thereby allowing one to study fundamental properties of these complex systems. We exploited this ability to control film microstructure in order to understanding chemical reactivity of interfaces and friction and wear behavior of ultra-thin oxide films.

Highlights of the results are discussed in the following sections; the reference numbers refer to journal publications that resulted from the project as listed in Section 11.

\section{Metal/TiO 2 Interfaces}

Potassium $/ \mathrm{TiO}_{2}$ Interfaces - Submonolayer and multilayer amounts of potassium were deposited onto $\mathrm{TiO}_{2}(110)$ surfaces. Potassium interacts strongly with the stoichiometric surface causing reduction of $\mathrm{Ti}^{4+}$ cations at the interface region and a large change in work function $[1,6,7$. At submonolayer coverages, the potassium donates charge to the oxygen anions thereby reducing the $\mathrm{Ti}$ cations. At larger $\mathrm{K}$ coverages, stable $\mathrm{K}_{2} \mathrm{O}$ multilayers are formed at room temperature via oxygen diffusion from the substrate, leaving behind an oxygen deficient $\mathrm{TiO}_{2-\mathrm{x}}$ interfacial composition. On defective $\mathrm{TiO}_{2}$ surfaces, the surface $\mathrm{Ti}$ cations are already in the $\mathrm{Ti}^{3+}$ valence state and the $\mathrm{K}$ is found to be less reactive.

Aluminum $/ \mathrm{TiO}_{2}$ Interfaces - Aluminum interacts strongly with both stoichiometric and substoichiometric $\mathrm{TiO}_{2}(110)$ surfaces at room temperature. For monolayer $\mathrm{Al}$ doses, charge transfer occurs from the $\mathrm{Al}$ to the surface Ti cations causing reduction of $\mathrm{TiO}_{2}$ and oxidation of the Al layer. At larger Al doses, an amorphous aluminum oxide film continues to grow by extracting oxygen anions from the $\mathrm{TiO}_{2}$ substrate, producing an $\mathrm{AlO}_{\mathrm{x}} / \mathrm{TiO}_{2-\mathrm{x}}$ "interphase" region across the $\mathrm{Al} / \mathrm{TiO}_{2}$ interface $[2,6,7,19]$.

Impurity Effects at the $\mathrm{Al} / \mathrm{TiO}_{2}$ Interface - The presence of intentionally-placed submonolayer amounts of carbon and potassium influences the $\mathrm{Al} / \mathrm{TiO}_{2}$ interfacial chemistry. Carbon interacts weakly with the $\mathrm{TiO}_{2}$ surface but retards the oxidation rate of the aluminum and decreases the thermal stability of the $\mathrm{AlO}_{\mathrm{x}}$ interphase [5,7]. Deposition of $\mathrm{Al}$ in the presence of sub-monolayer potassium impurities has minimal effect on the Al oxidation reaction but oxidized potassium species become incorporated in the aluminum oxide overlayer [7].

\section{Metal/NiO Interfaces}

Magnesium / NiO Interfaces - Mg deposited onto $\mathrm{NiO}(100)$ in UHV interacts with the oxygen anions of the $\mathrm{NiO}$ substrate in the initial stages, forming an $\mathrm{MgO}$ layer by extracting anions from 
the substrate $[6,9,15]$. Metallic $\mathrm{Mg}$ layers grow upon subsequent depositions. Annealing studies below the $\mathrm{Mg}$ desorption temperature show that $\mathrm{MgO}$ continually forms with further reduction of the Ni cations. A simple atomistic model suggests that the $\mathrm{MgO}$ is formed primarily by oxide extraction, and that the reduced $\mathrm{Ni}$ species are concentrated at the interface and do not diffuse into the overlayer.

Aluminum / NiO Interfaces - Aluminum does not become oxidized as it is deposited onto a $\mathrm{NiO}$ (100) surface, in contrast to the $\mathrm{Al} / \mathrm{TiO}_{2}$ system. An intermetallic $\mathrm{Ni}_{3} \mathrm{Al}$ phase forms at the interface with the same (100) orientation as the $\mathrm{NiO}$ substrate and the reaction is controlled by the extraction of $\mathrm{Ni}$ out of the $\mathrm{NiO}$ subsurface region $[3,6,15]$. At large doses of aluminum, metallic $\mathrm{Al}$ is formed on top of the $\mathrm{Ni}_{3} \mathrm{Al}$ phase and the overlayer has a very heterogeneous morphology. Defects and nonstoichiometry on the $\mathrm{NiO}(100)$ surface intentionally created prior to growth affect the disorder and roughness of the growing film but do not change the overall growth mechanism. Based on relative free energy of formation for bulk compounds, the aluminum is predicted to be oxidized. Therefore, this system demonstrates that interfacial thermodynamics and kinetics are important in controlling interface structure and composition.

\section{Metal/ $\mathrm{Al}_{2} \mathrm{O}_{3}$ Interfaces}

Magnesium / Sapphire Interfaces - During the initial deposition of Mg onto a r-cut sapphire ( $\alpha$ $\mathrm{Al}_{2} \mathrm{O}_{3}$ ) surface, very little interaction between the $\mathrm{Mg}$ and the $\mathrm{Al}_{2} \mathrm{O}_{3}$ substrate occurs and a very abrupt interface is formed. The first $\mathrm{Mg}$ monolayer exhibits spectroscopic features similar to $\mathrm{MgO}$ but all additional layers remain as metallic $\mathrm{Mg}[4,6,8,20]$. The metallic $\mathrm{Mg}$ film has a textured polycrystalline structure and desorbs from the surface upon annealing above $\sim 300^{\circ} \mathrm{C}$.

\section{Oxide/NiO Interfaces}

$\mathrm{MgO} / \mathrm{NiO}$ Interfaces - The less than 1\% lattice mismatch between $\mathrm{MgO}$ and $\mathrm{NiO}$ allows for extremely high quality epitaxial MgO films to be grown on $\mathrm{NiO}(100)[9,11,15,18]$. Negligible intermixing occurs at the substrate/overlayer interface and the $\mathrm{MgO} / \mathrm{NiO}$ structure remains stable up to $600^{\circ} \mathrm{C}$. High quality multilayered nanolaminate $\mathrm{MgO} / \mathrm{NiO}$ structures can be grown with excellent epitaxy. Above $600^{\circ} \mathrm{C}$, interdiffusion becomes significant leading to a ternary $\mathrm{Mg}-\mathrm{Ni}$ O structure.

Aluminum Oxide / NiO Interfaces - The structure and composition of the aluminum oxide / $\mathrm{NiO}$ interface is strongly temperature dependent. Deposition of $\mathrm{Al}$ in an $\mathrm{O}_{2}$ ambient at $800^{\circ} \mathrm{C}$ is accompanied by a vigorous interfacial reaction to form a $\mathrm{NiAl}_{2} \mathrm{O}_{4}$ spinel phase $[15,16]$. The spinel phase is highly epitaxial with $\mathrm{NiAl}_{2} \mathrm{O}_{4}(100)$ growing parallel to $\mathrm{NiO}(100)$. At lower temperature $\left(250^{\circ} \mathrm{C}\right)$, little interaction with the NiO substrate occurs and a homogeneous amorphous $\mathrm{AlO}_{\mathrm{x}}$ phase is produced. Post-deposition annealing of the amorphous $\mathrm{AlO}_{\mathrm{x}}$ layer results in strong reaction with the $\mathrm{NiO}$ substrate leading to the crystallization of the $\mathrm{NiAl}_{2} \mathrm{O}_{4}$ spinel phase.

\section{Oxide $/ \mathrm{Al}_{2} \mathrm{O}_{3}$ Interfaces}

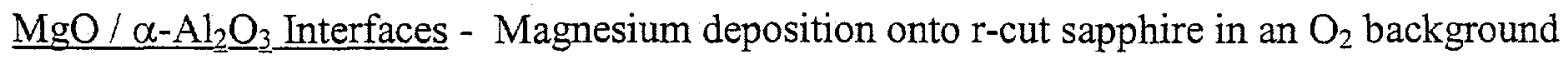
leads to the formation of a random polycrystalline $\mathrm{MgO}$ overlayer [6,8]. After extended high 
temperature annealing $\left(>60 \mathrm{~min}\right.$ at $900^{\circ} \mathrm{C}$ ) the polycrystalline $\mathrm{MgO}$ phase recrystallizes into $\mathrm{MgO}$ clusters oriented with $\mathrm{MgO}(100)$ parallel to the r-cut sapphire substrate.

\section{ECR-Plasma-Assisted Growth of Oxide Films}

Al(O) Alloys and $\mathrm{AlO}_{x}$ Films - $\mathrm{Al}_{2} \mathrm{O}_{3}$ and $\mathrm{AlO}_{\mathrm{x}}$ layers were grown on $\mathrm{Si}(100)$ substrates using ECR oxygen-plasma-assisted e-beam evaporation of aluminum. Deposition temperature and ion energy markedly affect the surface texture and film microstructure. The $\mathrm{Al}_{2} \mathrm{O}_{3}$ films consist of amorphous and/or small grain nanocrystalline $\gamma-\mathrm{Al}_{2} \mathrm{O}_{3}$ microstructure, whereas the substoichiometric $\mathrm{AlO}_{\mathrm{x}}$ films are larger grain polycrystalline $\mathrm{Al}$ containing a fine dispersion of $\gamma$ $\mathrm{Al}_{2} \mathrm{O}_{3}$ precipitates $[12,14]$. These films exhibit very high hardness and yield stress [13]. This work was done in collaboration with J. Charles Barbour at Sandia-Albuquerque.

Heteroepitaxial Zirconia Films on Sapphire Substrates - Stoichiometric $\mathrm{ZrO}_{2}$ films were grown on $r$-cut sapphire substrates by evaporating $\mathrm{Zr}$ in the presence of an ECR oxygen plasma. High quality epitaxial monoclinic or cubic $\mathrm{ZrO}_{2}$ phases were produced depending on growth temperature and deposition rate $[17,22,23]$. The films are highly epitaxial and exhibit a three dimensional surface morphology. Above $475^{\circ} \mathrm{C}$, the r-cut sapphire lattice induces epitaxial c$\mathrm{ZrO}_{2}$ film growth without the addition of stabilizing dopants as long as the deposition rate is maintained below $0.5 \AA / \mathrm{s}$. At higher growth rates, the thermodynamically favored $\mathrm{m}-\mathrm{ZrO}_{2}$ phase forms epitaxially due to limited surface migration of adsorbed species during growth.

Cubic Zirconia Films on $\mathrm{SiO}_{2}$ Substrates - Pure stoichiometric $\mathrm{ZrO}_{2}$ films were deposited onto amorphous silica substrates by electron beam evaporation of $\mathrm{Zr}$ in the presence of an electron cyclotron resonance (ECR) oxygen plasma. Grain size, strain and texture were analyzed by Xray diffraction (XRD) and reflection high energy electron diffraction (RHEED). Films grown at room temperature are polycrystalline and exist in the cubic phase $[23,25]$. Growth at elevated temperatures produces coexisting cubic and monoclinic phases and shows a maximum critical grain size of $\sim 10 \mathrm{~nm}$ for stabilization of the cubic phase. Pole figure analysis indicates a preferred cubic [200] fiber axis for room temperature growth and dual monoclinic $\{111\}$ and $\{11 \overline{1}\}$ in-plane textures for films grown at $400^{\circ} \mathrm{C}$. Post deposition annealing experiments confirm the existence of a critical grain size and suggest mechanisms for grain growth.

\section{Friction and Wear of Zirconia Films}

Effect of $\mathrm{ZrO}_{2}$ Film Microstructure - Unlubricated sliding of sapphire and stainless steel sliders on zirconia films containing different microstructures show a critical correlation between friction and wear characteristics and film microstructure $[23,24]$. Pin-on-disk testing revealed that "random" polycrystalline films have the highest film wear and friction coefficients $<0.35$. For a "highly oriented" polycrystalline zirconia microstructure, similar friction coefficients coupled with negligible wear on either the counterface or film was observed. The presence of a "random" polycrystalline component intermixed with a "highly oriented" microstructure results in friction coefficients $\sim 1$ due to a transfer film of counterface material. Macro-scale pin-ondisk and micro-scale friction microprobe tests indicate that frictional phenomena scale consistently. An "oriented/random" film microstructure causes an anisotropic cracking during scratch testing which is attributed to fracture primarily in the "oriented" component of the film. This work was done in collaboration with Peter Blau at Oak Ridge National Lab in the High Temperature Materials Laboratory General User Facility. 


\section{Graduate Student Degrees Resulting from the Project}

Linda Dake, Ph.D., Physics (May 1995)

"Surface and Interface Properties of Metal / $\mathrm{TiO}_{2}$ (110) Systems"

Syed Imaduddin, Ph.D., Physics (December 1996)

"Properties of Ultra-thin Metal and Oxide Films on NiO (100)"

Scott Moulzolf, Ph.D., Physics (August 1999)

"Synthesis and Characterization of $\mathrm{ZrO}_{2}$ Thin Films with Controlled Microstructure"

Yan Yu, Ph.D., Physics (expected Aug. 2000)

"Interaction of Mg and MgO Ultra-thin Films with Sapphire Surfaces"

David Marshall, M.S., Physics (August 1996)

"Surface Morphology and Film Microstructure of $\mathrm{Al}(\mathrm{O})$ and $\mathrm{Al}_{2} \mathrm{O}_{3}$ Thin Films Grown by ECR Plasma Deposition"

Frank Bock, M.S., Physics (expected Aug. 2000)

"Synthesis and Characterization of Silver Oxide Films Grown by ECR Plasma Deposition"

\section{Undergraduate Students that Worked on the Project}

Thomas Cole (spring 1990) "Design, Fabrication, Calibration of a Metal Evaporation Source" Elizabeth Dyer (fall 1992) "Polishing of NiO Single Crystals"

David Marshall (spring 1994) "Apparatus for Measuring RHEED Intensities"

Paul Sasso (spring 1994) "Construction of a Multi-Source Metal Evaporator"

Amiee Davidson (summer 1994) "Studies of MgO/NiO Interfaces"

Sam Hess (summer 1995) "Studies of Polished and Annealed $\mathrm{TiO}_{2}$ Surfaces"

Adrian Knight (summer 1995) "AFM Imaging of Ultra-Thin Films on Sapphire"

Jason Patterson (fall 1997) "Substrate Preparation and Thin Film Thickness Measurements"

Scott Cookson (summer 1997) "Atomic Force Microscopy of Ceramic Films"

LeKisha Pringle (summer 1997) "X-ray Photoelectron Spectroscopy of Ceramic Films"

Luke Doucette (summer 1999) "Synthesis and Characterization of $\mathrm{Al}_{2} \mathrm{O}_{3}$ and AIN Films" 


\section{Publications Resulting from DOE Grant \# DE-FG02-90ER45417}

1. "Electronic and Structural Properties of Interfaces Created by Potassium Deposition on $\mathrm{TiO}_{2}$ (110) Surfaces," R.J. Lad and L.S. Dake, Mat. Res. Soc. Symp. Proc. 238, 823 (1992).

2. "Electronic and Chemical Interactions at Aluminum / $\mathrm{TiO}_{2}(110)$ Interfaces," L.S. Dake and R.J. Lad, Surface Science 2899, 297 (1993).

3. "Aluminum Deposition on $\mathrm{NiO}(100)$ : Growth, Structure and Composition of the Interface," S. Imadduddin and R.J. Lad, Surface Science 290, 35 (1993).

4. "Structure and Morphology of Clean and Magnesium - Dosed Sapphire Surfaces," Yan Yu and R.J. Lad, Mat. Res. Soc. Symp. Proc. 317, 583 (1994).

5. "Properties of Aluminum Overlayers on Chemically Modified $\mathrm{TiO}_{2}$ (110) Surfaces," L.S. Dake and R.J. Lad, J. Vac. Sci. Technol. A 13 , 122 (1995).

6. "Interactions at Metal / Oxide and Oxide / Oxide Interfaces Studied by Ultra-thin Film Growth on Single-Crystal Oxide Substrates," R.J. Lad, Surface Review and Letters 2 , 109 (1995).

7. "Surface and Interface Properties of Metal / $\mathrm{TiO}_{2}$ (110) Systems," Linda S. Dake, Ph.D. Thesis, University of Maine (May 1995).

8. "Chemical Bonding, Structure, and Morphology of $\mathrm{Mg} / \alpha-\mathrm{Al}_{2} \mathrm{O}_{3}$ and $\mathrm{MgO} / \alpha-\mathrm{Al}_{2} \mathrm{O}_{3}$ Interfaces," Yan Yu and R.J. Lad, Mat. Res. Soc. Symp. Proc. 357, 47 (1995).

9. "Heteroepitaxial Growth of MgO Films on NiO (100) Single Crystal Surfaces," S. Imaduddin, A.M. Davidson, and R.J. Lad, Mat. Res. Soc. Symp. Proc. 357, 177 (1995).

10. "Surface Structure of Crystalline Ceramics" R.J. Lad, Chapter 5 in Physical Structure; Volume One of the Handbook of Surface Science, Ed. W.N. Unertl, (Elsevier, Amsterdam,1996) pp. 185-228.

11. "Growth and Stability of MgO / NiO Multilayered Films on Single Crystal NiO (100)," S. Imaduddin and R.J. Lad, Mat. Res. Soc. Symp. Proc. 401, 507 (1996).

12. "Surface Morphology and Microstructure of Al-O Alloys Grown By ECR Plasma Deposition," D.A. Marshall, J.C. Barbour, D.M. Fallstaedt, A.J. Howard, and R.J. Lad, Mat. Res. Soc. Symp. Proc. $\underline{396}, 497$ (1996).

13. "Low-Energy Deposition of High-Strength $\mathrm{Al}(\mathrm{O})$ Alloys from an ECR Plasma," J.C. Barbour, D.M. Follstaedt, J.A. Knapp, D.A. Marshall, S.M. Myers, and R.J. Lad, Mat. Rès. Soc. Symp. Proc. $\underline{403}, 235$ (1996).

14. "Surface Morphology and Film Microstructure of $\mathrm{Al}(\mathrm{O})$ and $\mathrm{Al}_{2} \mathrm{O}_{3}$ Thin Films Grown by ECR Plasma Deposition," David Marshall, M.S. Thesis, University of Maine (August 1996). 
15. "Properties of Ultra-thin Metal and Oxide Films on NiO (100)," Syed Imaduddin, Ph.D. Thesis, University of Maine (December 1996).

16. "Structure and Composition of Oxidized Aluminum on NiO (100)," S. Imaduddin and R.J. Lad, J. Vac: Sci. Technol. 15, 1211 (1997).

17. "Properties of $\mathrm{ZrO}_{2}$ Films on Sapphire Prepared by ECR Oxygen Plasma-Assisted Deposition," S.C. Moulzolf, Yan Yu, D.J. Frankel, and R.J. Lad, J. Vac. Sci. Technol. 15, 1211 (1997).

18. "Epitaxial MgO (100) Film Grown on a NiO (100) Single Crystal Surface Studied by XPS and UPS," S. Imaduddin and R.J. Lad, Surface Science Spectra 4, 194 (1998)

19. "Ultra-thin Al Overlayers on Clean and K-Covered $\mathrm{TiO}_{2}$ (110) Surfaces," L.S. Dake and R.J. Lad, Surface Science Spectra 4, 232 (1998)

20. "R-cut Sapphire Surface Spectra by XPS and UPS: Clean Surface and Ultra-thin Mg Films," Yan Yu and R.J. Lad, Surface Science Spectra 4, 207 (1998)

21. “A Novel Shutter Design," S.C. Moulzolf, D.J. Frankel, and R.J. Lad, J. Vac. Sci. Technol. A 16,766 (1998) 46.

22. "Electron Cyclotron Resonance Oxygen-Plasma-Assisted Deposition of $\mathrm{ZrO}_{2}$," S.C. Moulzolf and R.J. Lad, Handbook of Thin Film Process Technology, Ed. D.A. Glocker and S.I. Shah (IOP Publishing, Philadelphia, PA, 1998) pp. X3.8.1-4.

23. "Synthesis and Characterization of $\mathrm{ZrO}_{2}$ Thin Films with Controlled Microstructure," Scott Moulzolf, Ph.D. Thesis, University of Maine (August 1999).

24. "Microstructural Effects on the Friction and Wear of Zirconia Films in Unlubricated Sliding Contact," S.C. Moulzolf, R.J. Lad, and P.J. Blau, Thin Solid Films 347, 223 (1999)

25. "Diffraction Studies of Cubic Phase Stability in Undoped Zirconia Thin Films," S.C. Moulzolf and R.J. Lad, Journal of Materials Research, in press (1999).

\section{Presentations}

1. "Electronic Structure of Surface Defects on $\mathrm{TiO}_{2}(110)$ Studied by Resonant Photoemission," Meeting of the American Physical Society, Anaheim, CA, March 1990 (Talk by R.J. Lad).

2. "Properties of Potassium Modified $\mathrm{TiO}_{2}$ (110) Surfaces," American Vacuum Society 36th National Symposium, Toronto, Canada, October 1990. (Poster by R.J. Lad).

3. "Structure, Adhesion, and Stability of Metal Overlayers on $\mathrm{TiO}_{2}$ and NiO Surfaces," American Ceramic Society Symposium on Atomic Structure, Bonding, and Properties of Ceramics, Marco Island, FL, October 1991 (Talk by R.J. Lad). 
4. "Structure and Chemical Bonding of Metal Overlayers on $\mathrm{NiO}$ and $\mathrm{TiO}_{2}$ Surfaces," American Vacuum Society 37th National Symposium, Seattle, WA, November 1991 (Talk by R.J. Lad).

5. "Electronic and Structural Properties of Interfaces Created by Potassium Deposition on $\mathrm{TiO}_{2}$ (110) Surfaces," Fall Meeting of the Materials Research Society, Boston, MA, December 1991. (Poster by R.J. Lad).

6. "Electronic and Structural Properties of Ceramic Surfaces: An Overview," Department of Materials Science \& Engineering Seminar, Cornell University, Ithaca, NY, March 1992 (Talk by R.J. Lad).

13. "Electronic and Chemical Interactions at Aluminum/ $\mathrm{TiO}_{2}$ Interfaces," Conference on the Physics and Chemistry of Metal/Oxide Interfaces, Rutgers University, Piscataway, NJ, September 1992 (Poster by L. Dake).

14. "Structure and Morphology of Aluminum Overlayers on $\mathrm{NiO}(100)$ Interfaces," Conference on the Physics and Chemistry of Metal/Oxide Interfaces, Rutgers University, Piscataway, NJ, September 1992 (Poster by S. Imaduddin).

15. "Adhesion and Stability of Aluminum Films on $\mathrm{TiO}_{2}$ Surfaces," 95th Meeting of the American Ceramic Society, Cincinnati, OH, April 1993 (Talk by R.J. Lad).

16. "Structure and Composition of $\mathrm{Al} / \mathrm{NiO}$ Interfaces," 95th Meeting of the American Ceramic Society, Cincinnati, OH, April 1993 (Talk by R.J. Lad).

17. "Growth and Reactivity of Aluminum Overlayers on Stoichiometric and Chemically Modified $\mathrm{TiO}_{2}$ (110) Surfaces," 40th National Symposium of the American Vacuum Society, Orlando, FL, November 19, 1993 (Talk by L. Dake)

18. "Structure and Morphology of Clean and Magnesium-Dosed Sapphire Surfaces," Fall Meeting of the Materials Research Society, Boston, MA, December 2, 1993 (Poster by Yu Yan)

19. "Structural, Electronic, and Chemical Properties of Metal / Oxide Interfaces," Department of Chemistry Seminar, University of Maine, December 7, 1993 (Talk by R.J. Lad).

20. "Evolution of Surface Roughness and the Morphology of Aluminum Overlayers on $\mathrm{TiO}_{2}$ (110) Surfaces," Meeting of the American Physical Society, Pittsburgh, PA, March 22, 1994 (Talk by D. Marshall)

21. "Structure and Composition of Al / NiO (100) Interfaces Formed in an Oxygen Atmosphere," Meeting of the American Physical Society, Pittsburgh, PA, March 25, 1994 (Talk by S. Imaduddin)

22. "Interactions at Interfaces Formed by Magnesium Deposition onto $\alpha-\mathrm{Al}_{2} \mathrm{O}_{3}$ Surfaces," Meeting of the American Physical Society, Pittsburgh, PA, March 25, 1994 (Talk by R.J. Lad).

23. "Interactions at Metal / Oxide and Oxide / Oxide Interfaces," Eleventh International Summer Institute in Surface Science, University of Wisconsin-Milwaukee, June 3, 1994 (Invited Talk by R.J. Lad)

24. "Heteroepitaxial Growth of MgO films on NiO (100) Single Crystal Surfaces," Fall Meeting of the Materials Research Society, Boston, MA, November 30, 1994 (Talk by S. Imaduddin). 
25. "Chemical Bonding, Structure and Morphology of $\mathrm{Mg} / \alpha-\mathrm{Al}_{2} \mathrm{O}_{3}$ and $\mathrm{MgO} / \alpha-\mathrm{Al}_{2} \mathrm{O}_{3}$ Interfaces," Fall Meeting of the Materials Research Society, Boston, MA, December 2, 1994 (Poster by Y. Yan).

26. "Epitaxial Growth of $\mathrm{MgO} / \mathrm{NiO}$ Multilayers on $\mathrm{NiO}$ (100) Substrates," Meeting of the American Physical Society, San Jose, CA, March 22, 1995 (Talk by R.J. Lad)

27. "Tribological Properties of Electron Cyclotron Resonance Deposited $\mathrm{AlO}_{\mathrm{x}}$ and $\mathrm{Al}_{2} \mathrm{O}_{3}$ Films," Workshop on the Physical and Chemical Mechanisms in Tribology, Bar Harbor, Maine, August 29, 1995 (Poster by D. Marshall).

28. "Morphology and Thermal Stability of MgO / NiO Interfaces," 42nd National Symposium of the American Vacuum Society, Minneapolis, MN, October 20, 1995 (Talk by S. Imaduddin).

29. "Epitaxial Growth of MgO/ NiO Multilayered Films on $\mathrm{NiO}(100)$," 1995 Fall Meeting of the the Materials Research Society Fall, Boston, MA, November 30, 1995 (Talk by S. Imaduddin).

30. "Surface Morphology and Film Microstructure of Electron Cyclotron Resonance Deposited $\mathrm{AlO}_{\mathrm{x}}, " 1995$ Fall Meeting of the the Materials Research Society Fall Boston, MA, November 29, 1995 (Talk by D. Marshall).

31. "Low-Energy Deposition of High-Strength Al(O) Alloys from an ECR Plasma," 1995 Fall Meeting of the the Materials Research Society Fall, Boston, MA, November 29, 1995 (Talk by J.C. Barbour).

32. "Synthesis, Characterization and Performance of Oxide Films for Microsensor and Tribology Applications," Molecular Sciences Center, Battelle Pacific Northwest Laboratory, Richland, WA, September 18, 1996 (Talk by R.J. Lad)

33. "Controlled Growth of Oxide Films Using Molecular Beam Epitaxy Techniques," Pacific Northwest American Vacuum Symposium, Troutdale, OR, September 19, 1996 (Invited talk by R.J. Lad)

34. "Structure and Composition of Oxidized Aluminum on NiO (100)," 43rd National Symposium of the American Vacuum Society, Philadelphia, PA, October 17, 1996 (Talk by S. Imaduddin)

35. "Properties of $\mathrm{ZrO}_{2}$ Films on Sapphire Prepared by ECR Oxygen Plasma-Assisted Deposition," 43rd National Symposium of the American Vacuum Society, Philadelphia, PA, October 17, 1996 (Talk by S. Moulzolf)

36. "ECR Oxygen Plasma-Assisted Growth of Epitaxial Zirconia Films," 1996 Fall Meeting of the Materials Research Society, Boston, MA, December 2, 1996 (Talk by S. Moulzolf)

37. "Initial Stages of Epitaxial Growth of Metastable $\mathrm{ZrO}_{2}$ and $\mathrm{WO}_{3}$ Films on Sapphire," 1997 Spring Meeting of the Materials Research Society, San Francisco, CA, April 2, 1997 (Talk by R.J. Lad)

38. "Chemical Bonding, Structure, and Morphology of $\mathrm{Mg} / \alpha-\mathrm{Al}_{2} \mathrm{O}_{3}$ Interfaces," 1997 Meeting of the New England Section - American Physical Society, Orono, ME, April 11, 1997 (Talk by $\mathrm{Y} . \mathrm{Yu}$ )

39. "MBE Synthesis and Tribological Properties of Oxide Films," Argonne National Laboratory, May 2, 1997 (Invited Talk by R.J. Lad) 
40. "Microstructural Effects on the Friction and Wear of $\mathrm{ZrO}_{2}$ Films," 1997 Fall Meeting of the Materials Research Society, Boston, MA, December 3, 1997 (Talk by S. Moulzolf)

41. "Characterization of Ultra-Thin Mg and MgO Films on Sapphire," Meeting of the American Physical Society, Los Angeles, CA, March 17, 1998 (Talk by Yan Yu).

42. "Synthesis and Properties of Ceramic Films Formed by Molecular Beam Epitaxy," Department of Chemistry Seminar, University of Maine, March 24, 1998 (Talk by R.J. Lad)

43. "ECR Oxygen-Plasma-Assisted Growth of Hard Zirconia Films on Sapphire," 25th International Conference on Metallurgical Coatings and Thin Films, San Diego, CA, April 28, 1998 (Poster by S. Moulzolf)

44. "Influence of Sapphire Orientation on Heteroepitaxial Zirconia Film Growth," Meeting of the American Physical Society, Atlanta, GA, March 26, 1999 (Talk by S. Moulzolf)

45. "Room Temperature Growth of Cubic Zirconia Films without Cation Dopants," Meeting of the American Physical Society, Atlanta, GA, March 26, 1999 (Talk by S. Moulzolf) 